\title{
Median QA Interval
}

National Cancer Institute

\section{Source}

National Cancer Institute. Median QA Interval. NCI Thesaurus. Code C120923.

The median time period between the recording of a Q wave on ECG and the onset of the aortic blood pressure pulse as determined over a number of cardiac cycles during a given interval of time. 